\title{
RESEARCH
}

Open Access

\section{hERG-deficient human embryonic stem cell-derived cardiomyocytes for modelling QT prolongation}

\author{
Yun Chang ${ }^{1,2+}$, Ya-nan $\mathrm{Li}^{1,2+}$, Rui Bai ${ }^{1,2}$, Fujian $\mathrm{Wu}^{1,2}$, Shuhong Ma ${ }^{1,2}$, Amina Saleem ${ }^{1,2}$, Siyao Zhang ${ }^{1,2}$, \\ Youxu Jiang ${ }^{1,2}$, Tao Dong ${ }^{1,2}$, Tianwei Guo ${ }^{1,2}$, Chengwen Hang ${ }^{3}$, Wen-jing Lu ${ }^{1,2}$, Hongfeng Jiang ${ }^{1,2^{*}}$ and \\ Feng $\operatorname{Lan}^{1,2,4^{*}}$
}

\begin{abstract}
Background: Long-QT syndrome type 2 (LQT2) is a common malignant hereditary arrhythmia. Due to the lack of suitable animal and human models, the pathogenesis of LQT2 caused by human ether-a-go-go-related gene (hERG) deficiency is still unclear. In this study, we generated an hERG-deficient human cardiomyocyte (CM) model that simulates 'human homozygous hERG mutations' to explore the underlying impact of hERG dysfunction and the genotype-phenotype relationship of hERG deficiency.

Methods: The KCNH2 was knocked out in the human embryonic stem cell (hESC) H9 line using the CRISPR/Cas9 system. Using a chemically defined differentiation protocol, we obtained and verified hERG-deficient CMs. Subsequently, high-throughput microelectrode array (MEA) assays and drug interventions were performed to characterise the electrophysiological signatures of hERG-deficient cell lines.

Results: Our results showed that $\mathrm{KCNH} 2$ knockout did not affect the pluripotency or differentiation efficiency of $\mathrm{H} 9$ cells. Using high-throughput MEA assays, we found that the electric field potential duration and action potential duration of hERG-deficient CMs were significantly longer than those of normal CMs. The hERG-deficient lines also exhibited irregular rhythm and some early afterdepolarisations. Moreover, we used the hERG-deficient human CM model to evaluate the potency of agents (nifedipine and magnesium chloride) that may ameliorate the phenotype.

Conclusions: We established an hERG-deficient human CM model that exhibited QT prolongation, irregular rhythm and sensitivity to other ion channel blockers. This model serves as an important tool that can aid in understanding the fundamental impact of hERG dysfunction, elucidate the genotype-phenotype relationship of hERG deficiency and facilitate drug development.
\end{abstract}

Keywords: Human ether-a-go-go-related gene, $\mathrm{KCNH} 2$, hESCS, QT prolongation, CRISPR/Cas9

\footnotetext{
*Correspondence: hfjiang@ccmu.edu.cn; fenglan@ccmu.edu.cn

${ }^{\dagger}$ Yun Chang and Ya-nan Li contributed equally to this work.

${ }^{1}$ Beijing Laboratory for Cardiovascular Precision Medicine, The Key Laboratory

of Biomedical Engineering for Cardiovascular Disease Research, The Key

Laboratory of Remodeling-Related Cardiovascular Disease, Ministry of

Education, Beijing Anzhen Hospital, Capital Medical University, Research

Institute Building, Room 323, 2 Anzhen Road, Chaoyang District, Beijing

100029, China

Full list of author information is available at the end of the article
}

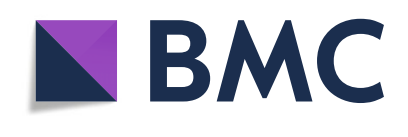

(- The Author(s). 2021 Open Access This article is licensed under a Creative Commons Attribution 4.0 International License, which permits use, sharing, adaptation, distribution and reproduction in any medium or format, as long as you give appropriate credit to the original author(s) and the source, provide a link to the Creative Commons licence, and indicate if changes were made. The images or other third party material in this article are included in the article's Creative Commons licence, unless indicated otherwise in a credit line to the material. If material is not included in the article's Creative Commons licence and your intended use is not permitted by statutory regulation or exceeds the permitted use, you will need to obtain permission directly from the copyright holder. To view a copy of this licence, visit http://creativecommons.org/licenses/by/4.0/. The Creative Commons Public Domain Dedication waiver (http://creativecommons.org/publicdomain/zero/1.0/) applies to the data made available in this article, unless otherwise stated in a credit line to the data. 


\section{Background}

The KCNH2 encodes the voltage-gated $\mathrm{K}^{+}$channel $\alpha$ subunit, Kv11.1, which is known as the human ether-ago-go-related gene (hERG) [1]. The hERG channel constitutes a rapidly activated delayed rectifier $\mathrm{K}^{+}$channel (IKr) in the heart [2] and is responsible for myocardial cell repolarisation when the cardiac action potential ends [3]. Previous evidence shows that $\mathrm{KCNH} 2$ mutations are associated with hereditary long-QT syndrome type 2 (LQT2) [4]. The prevalence of LQT2 accounts for $25-40 \%$ of all long-QT syndrome (LQTS) types and is one of the most common inherited arrhythmias [5]. Generally, LQT2 has the characteristics of a prolonged QT interval and action potential duration (APD), which predispose patients to torsade de pointes, a type of polymorphic ventricular tachycardia and sudden cardiac death [6-8].

In most studies, to better understand the pathogenesis, the establishment of models that reveal disease mechanisms is crucial. Surprisingly, to date, although human homozygous hERG mutations have been reported, an appropriate model of human hERG deficiency has not been established. Transgenic mice expressing an hERG dominant-negative construct exhibited mild APD prolongation in individual myocytes, but QT prolongation was not observed in intact animals [9]. Targeted disruption of Erg1a in mice led to a homozygous embryonic lethal phenotype, whereas heterozygotes showed slight QT prolongation [10]. Since previous models failed to reproduce the disease phenotype, we should consider that the human heart is distinctly different from the murine heart. Mice have a faster heart rate (500-700 bpm) than humans, which represents different action potentials and repolarising $\mathrm{K}^{+}$currents. In mice, the dominant cardiac repolarisation $\mathrm{K}^{+}$currents are fast and slow transient outward currents and delayed rectifier voltage-gated $\mathrm{K}^{+}$currents (IK, slow1 and IK, slow2), while the role of $\mathrm{IKr}$ is minimal [11-13]. Thus, the need to establish an hERG-deficient model to determine the pathological mechanism of this disease is urgent.

Recently, cardiomyocytes (CMs) derived from human embryonic stem cells (hESCs)/human pluripotent stem cells (hPSCs) have been used for modelling various hereditary cardiomyopathies [14, 15]. Numerous studies have shown that hESC and hPSC have high similarity [16-18]. LQTS was one of the first cardiac diseases that was recapitulated in hPSC models [19]. To date, cell models derived from LQTS mutation carriers have been widely used in mechanistic studies and for drug screening [20-22]. However, cell lines from different individuals contain additional genetic variants, which may limit the observation of genotype-phenotype relationships. Furthermore, there are several hERG heterozygous mutations, diverse phenotype of loss-of-function and different mutation mechanisms [23-25], which makes the research on the pathological mechanisms of hERG functional dysfunction more complicated. Furthermore, in individuals with heterozygous mutations, the presence of wild-type (WT) alleles may affect repolarisation. In cases that were heterozygous for R176W in $293 \mathrm{~T}$ cells, hERG tail current density was reduced by $\sim 75 \%$ [26]. Nevertheless, in hPSC-CMs from a heterozygous R176W individual, a $\sim 43 \%$ decrease in $\mathrm{IKr}$ density was observed [27]. The reasons for this observed discrepancy in cases with the same mutation are unknown but may involve the differential expression of WT and mutant alleles. Therefore, an appropriate hERG-deficient model, rather than mutation-based models, is desperately needed to determine the well-defined genotype-phenotype correspondence.

Here, we generated an hERG-deficient human CM model using the CRISPR/Cas9 system. After differentiation into CMs and characterisation by electrophysiology and drug intervention, the cell lines exhibited QT prolongation, irregular rhythm, early afterdepolarisation (EAD) occurrence and IKr current insensitivity. Additionally, nifedipine and magnesium chloride $\left(\mathrm{MgCl}_{2}\right)$ could reverse the observed phenotype. Therefore, this model is appropriate for elucidating the pathogenesis of hERG dysfunction, defining genotype-phenotype correspondence and facilitating drug development.

\section{Methods}

\section{Cell culture and cardiac differentiation}

The human embryonic stem cell-H9 line (hESC-H9; provided by WiCell Institute Inc., Madison, WI, USA)/ human pluripotent stem cell (hPSC, provided by Cellapy: CA1002008, Beijing, China) and the derived cells were cultured primarily in E8 medium (Cellapy, China). The cells were passaged with $0.5-\mathrm{mM}$ EDTA-PBS solution (Cellapy) when the cells reached $80 \%$ confluence. CM differentiation was carried out using small moleculebased methods [28]. When spontaneous beating was obvious, hESC-CMs were purified by the lactic acid metabolism selection method [29].

\section{Genome editing}

KCNH2 single-stranded guide RNA (sgRNA) (GCATCG ACATGAACGCG) was designed using an online tool (http://crispr.mit.edu/). We electroporated the epiCRISPR vector and sgRNA (100- $\mu$ l electrotransformation solution (Cellapy) plus 2.5- $\mathrm{gg} \mathrm{KCNH} 2$ gRNA plasmid) into the cells using the 4D nuclear receptor system and the CA137 programme (Lonza, Germany). The transfected cells were seeded in 6-well plates and cultured overnight in E8 medium containing $10 \mu \mathrm{M}$ of Rho kinase inhibitor Y27632. The medium was changed the next day. Drug (puromycin) selection was initiated after $72 \mathrm{~h}$ of transfection at a lower concentration of $0.1 \mu \mathrm{g} / \mathrm{ml}$ for the first 
hour and then at $0.3 \mu \mathrm{g} / \mathrm{ml}$ until the transfected lines were stable. The surviving cells were collected in 48-well plates and amplified for polymerase chain reaction (PCR) screening.

\section{Western blot}

Cells were rinsed in PBS (Corning, USA) and harvested in a CardioEasy CM dissociation buffer (Cellapy). The cells were then rinsed again in PBS and pelleted by centrifugation twice at $1200 \mathrm{rpm}$ for $5 \mathrm{~min}$ each time. After removing the supernatant, SDS-PAGE proteinloading buffer (Beyotime, China) was added, and the cells were lysed by sonication and heat-denatured. According to the molecular weight of the protein, we configured a $10 \%$ separation gel and a $4 \%$ concentration gel for electrophoresis and performed gel transfer to a polyvinylidene difluoride membrane using a gel transfer device (Bio-Rad) over $120 \mathrm{~min}$. Then, we blocked the membrane with $5 \%$ skimmed milk for $1 \mathrm{~h}$ at room temperature. The membrane was incubated with the primary antibody overnight at $4{ }^{\circ} \mathrm{C}$, followed by incubation with the secondary antibody for $2 \mathrm{~h}$ at room temperature.

\section{Immunofluorescence}

Cells were seeded in 24-well plates, fixed with $4 \%$ paraformaldehyde (PFA) (Solarbio, China) for $10 \mathrm{~min}$, permeabilised with $0.5 \%$ Triton X-100 (Sigma, USA) for $15 \mathrm{~min}$ and blocked with 3\% BSA (Sigma) at room temperature for 30 min. The cells were incubated with the prepared primary antibody overnight at $4{ }^{\circ} \mathrm{C}$. The following day, the cells were rinsed three times in $1 \times$ PBS for 5 min each time. The cells were incubated with the secondary antibody at room temperature in the dark for $2 \mathrm{~h}$ and then rinsed three times in $1 \times$ PBS for 5 min each time. Data were collected using a confocal microscope (Leica DMI 4000B).

\section{RNA extraction and quantitative reverse transcription PCR (qRT-PCR)}

Total cellular RNA was extracted with TRIzol (Invitrogen, USA) and treated with DNase I (Beyotime, China) for approximately $30 \mathrm{~min}$ at $37^{\circ} \mathrm{C}$ to eliminate DNA contamination. RNA was reverse transcribed using the Prime-Script ${ }^{\mathrm{TM}}$ reverse transcription system (TaKaRa, Japan). Relative gene expression levels were examined by qRT-PCR using the iCycler iQ5 (Bio-Rad, USA) with TB Green ${ }^{\text {Tw }}$ Premix Ex Taq ${ }^{\text {tm }} I I$ (Takara). The relative quantification was calculated according to the ${ }^{\triangle} \mathrm{CT}$ method. All primer sequences are listed in Table S1.

\section{Flow cytometry}

CMs were dissociated into a single cell suspension in a CardioEasy CM dissociation buffer. Cells were then rinsed in PBS, fixed in 4\% PFA for $10 \mathrm{~min}$ and permeabilised in $0.5 \%$ Triton $\mathrm{X}-100$ for $15 \mathrm{~min}$. The primary antibody was applied for $60 \mathrm{~min}$, followed by incubation with the secondary antibody for $30 \mathrm{~min}$ at room temperature. The samples were then rinsed in PBS and assessed using FACS analysis (EPICS XL, Beckman).

\section{Microelectrode array (MEA) analysis}

CMs were digested in a CardioEasy CM dissociation buffer, after which $2 \times 10^{4}$ cells were plated on a microelectrode array (MEA) pre-coated with 5\% Matrigel (Cellapy). The next day, 300- $\mu \mathrm{l}$ medium was added to each well. After the CMs resumed spontaneous beating, the experimental data were recorded on a Maestro EDGE (Axion Biosystems, Inc., Atlanta, USA) according to the MEA manual. Cardiac Analysis Tool, AxIS Navigator, AxIS data export tool and Origin were used to analyse the data.

\section{Data analysis and statistics}

All experiments were repeated at least 3 times with duplicate samples. All data are displayed as the mean \pm standard error of mean. Two-sided Student's $t$ test and one-way ANOVA were used to determine statistical significance, and $P<0.05$ was considered statistically significant.

\section{Results}

\section{Establishment of homozygous hERG-deficient hESCs}

We established an hERG-deficient cell model from the hESC-H9 cell line using the CRISPR/Cas9 system [30]. First, we designed a highly specific sgRNA to target the KCNH2. Next, hESC-H9 cells were subjected to electroporation with a plasmid containing sgRNA and Cas9, followed by puromycin screening. To assess the editing features of cell colonies, we analysed colonies using PCR and Sanger sequencing. Finally, we selected homozygous (biallelic mutations) colonies with $-2 \mathrm{bp}$ and $-8 \mathrm{bp}$ (Fig. 1a). In addition, to determine whether $\mathrm{KCNH} 2$ knockout played the same role in different stem cell lines, we also established a $\mathrm{KCNH}^{-/-} \mathrm{hPSC}$ cell line using the same method (data not shown). The $\mathrm{KCNH}^{-1-}$ colonies exhibited normal morphology (Fig. S1A). In addition, we found that $\mathrm{KCNH}^{-/-}$lines expressed the pluripotency markers OCT4 and SSEA4 (Fig. 1b). Similarly, gene expression analysis confirmed the expression of pluripotency genes (NANOG, SOX2, DPPA4 and REX1) (Fig. 1c). $K C N H 2^{-1-}$ lines also had a normal karyotype (Fig. 1d). A teratoma formation assay revealed that $\mathrm{KCNH}^{-/-}$cell lines exhibited stem cell properties (Fig. S1A).

\section{hERG-deficient hESCs can differentiate into CMs}

Since the hERG channel protein is primarily expressed on CMs, we used small molecules with clear chemical compositions to induce the differentiation of stem cells 

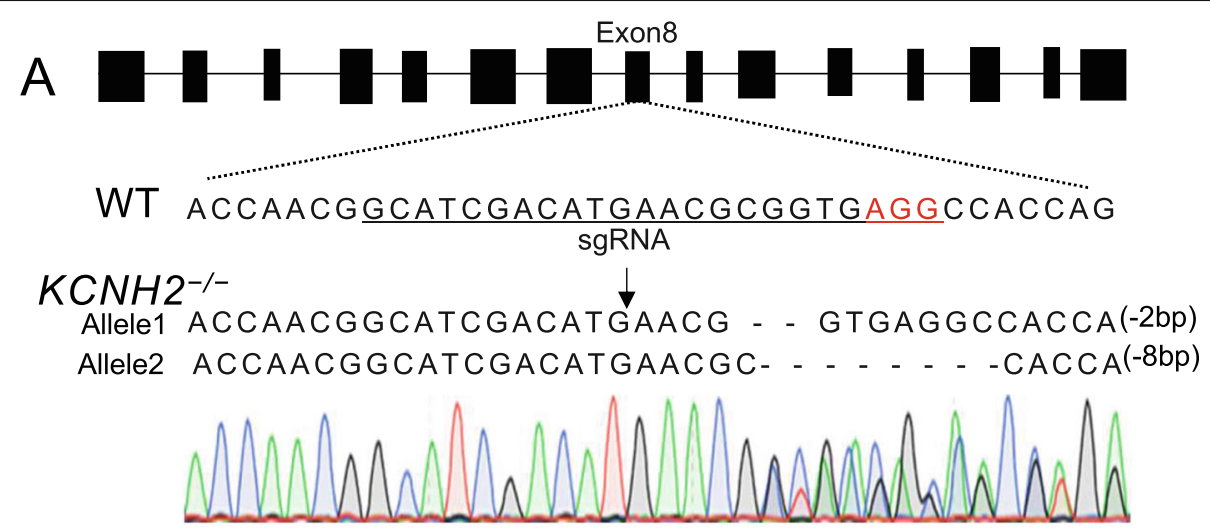

B
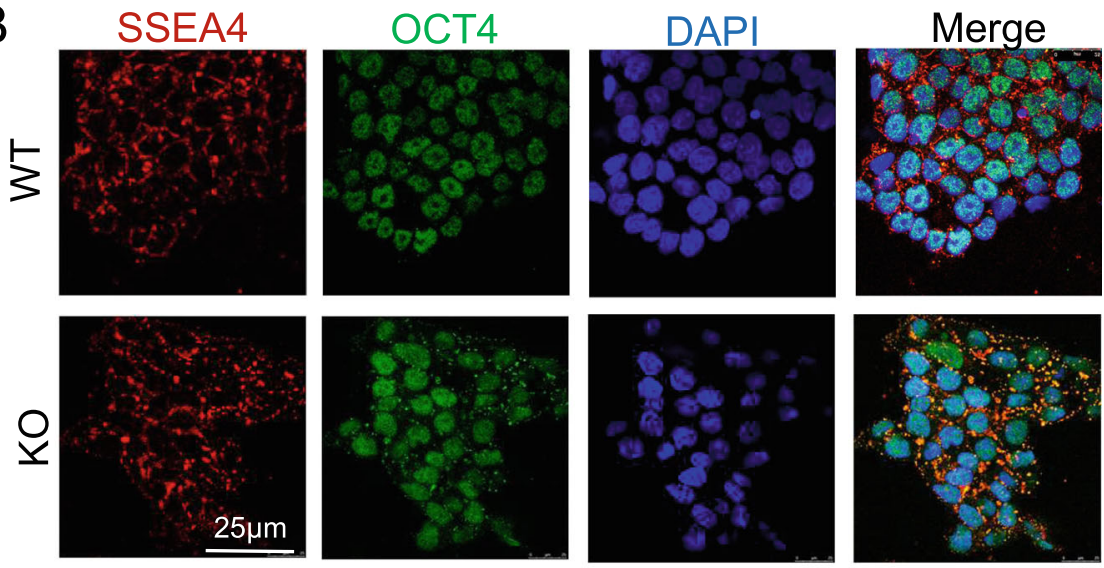

C

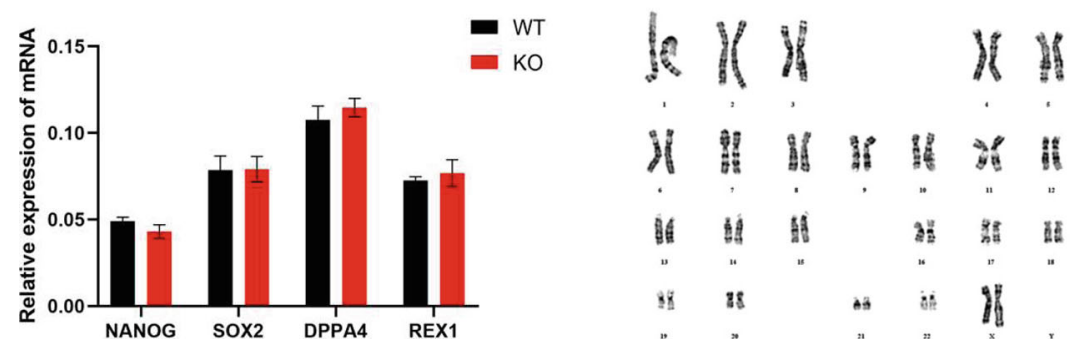

Fig. 1 hERG deficiency did not affect the pluripotency of hESCs. a Pattern diagram of KCNH2 knockout demonstrating the genic positions of their editing sites. b Pluripotency markers SSEA4 and OCT4 of cell lines immunofluorescent staining. Scale bar $=25 \mu \mathrm{m}$. $\mathbf{c}$ qRT-PCR analysis of pluripotency-related genes in $\mathrm{WT}$ and $\mathrm{KCNH}^{-/-}$. d Karyotype analysis revealed a normal karyotype of $46 \mathrm{chromosomes}$ in $\mathrm{KCNH}^{-/-}$

into CMs (Fig. 2a); 60-day-old cells were used for western blot, which confirmed the depletion of the hERG protein (Fig. 2b). To further probe the relevance of hERG in heart development, 30-day-old CMs were stained for troponin $\mathrm{T}$ (TNNT2) and $\alpha$-actinin (Fig. 2c). Next, flow cytometry showed that both WT and $\mathrm{KCNH}^{-/-} \mathrm{CMs}(\mathrm{KO})$ were nearly $85 \%$ TNNT2-positive (Fig. 2d, e). Additionally, we performed double immunostaining for MYL2 and MYL7 and revealed no significant changes in $\mathrm{CM}$ subsets (Fig. 2f, g). These results were consistent with those of a previous study [31]. Taken together, we demonstrated that hERG deficiency did not impact on myocardial differentiation.

\section{Responses to hERG blockers}

To determine the functions of an hERG-deficient model, the effect of two selective ion channel blockers on spontaneous field potential duration (FPD) was tested. E$4031(100 \mathrm{nM})[31,32]$ treatment caused prolongation in FPD in control CMs $(n=24)$, which demonstrated the presence of functional hERG channels. Moreover, treatment of WT cells with increasing concentrations of E- 


\begin{tabular}{|c|c|c|c|c|c|}
\hline E8 & \multicolumn{3}{|c|}{ RPMI+CDM3 } & RPMI without glucose+CDM3 & $\mathrm{RPMI+B27}$ \\
\hline $\operatorname{EDTA}(1: 6)$ & CHIR99021 & IWP2 & Maintenance & Glucose starvation & Maintenance \\
\hline
\end{tabular}
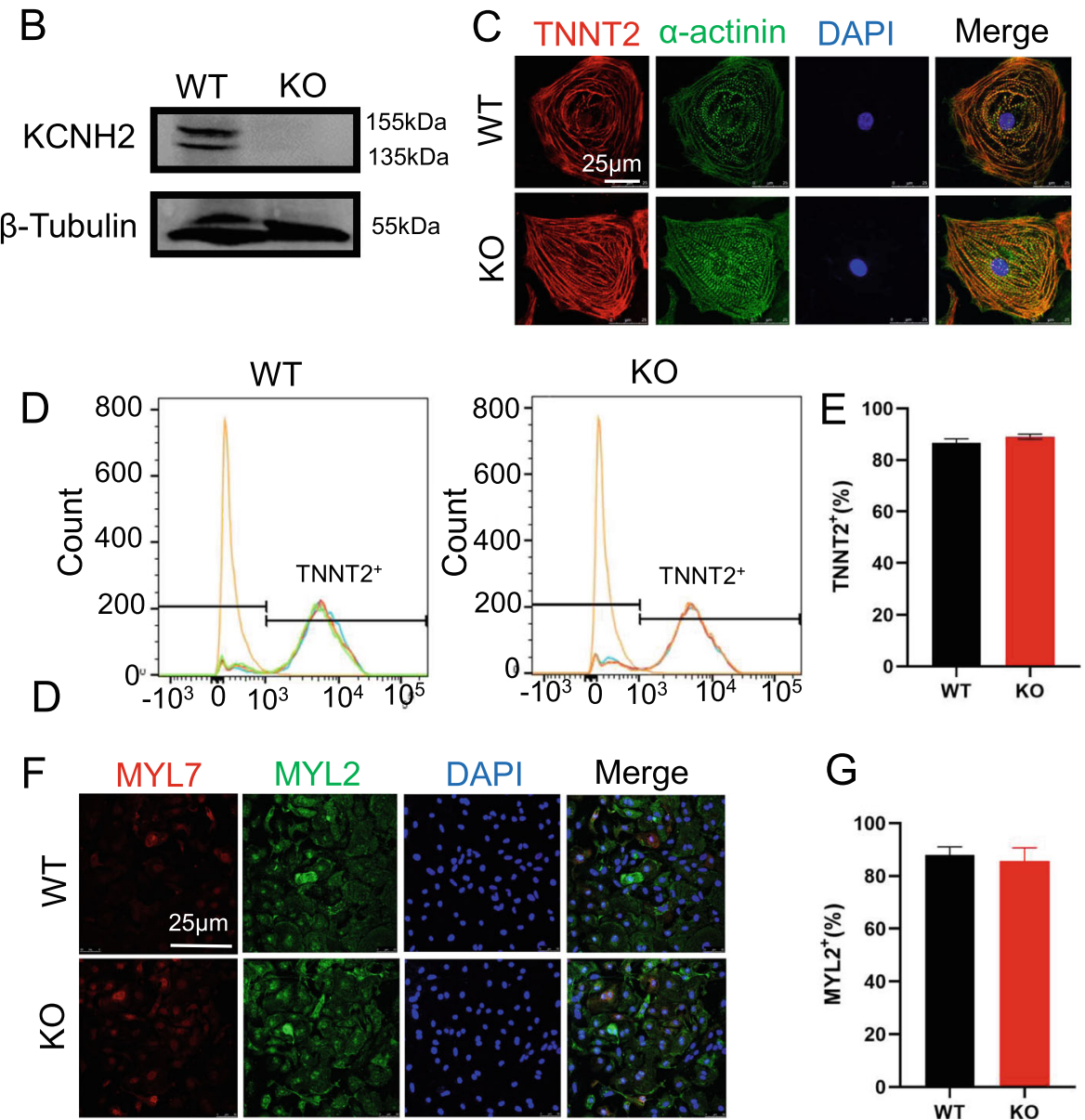

Fig. 2 hERG deficiency did not affect the differentiation of hESC-CMs. a Schematic illustration of hESCs in vitro differentiation protocols using small molecule-based methods. b The hERG expression assessed by western blotting analysis. c Immunofluorescence staining of cardiomyogenic differentiation markers TNNT2 and a-actinin. Scale bar $=25 \mu \mathrm{m}$. d, e Flow cytometry analyses of CMs marker TNNT2 expression at days 15 without purification. $\mathbf{f}, \mathbf{g}$ Immunostaining for the protein expression of MLC2V and MLC2a in WT and KOs. Scale bar $=25 \mu \mathrm{m}$. Data are expressed as means \pm S.E.M. of 3 independent experiments

4031 induced a dose-dependent increase in FPD (Fig. 3c, e). In contrast, the $\mathrm{KO}(n=24)$ exhibited insensitivity to different concentrations of E-4031 (Fig. 3d, f). Similar results were obtained with another hERG channel blocker, Dofetilide [33]. The KO exhibited almost no reaction, even with an extended reaction time (Fig. $3 g-j)$. This was expected as E-4031 and Dofetilide act primarily on the IKr current, and this current is absent in hERGdeficient CMs. These results demonstrated that we successfully generated an hERG dysfunction model.

\section{Irregular rhythm and EAD occurrence}

Previous studies showed that $\mathrm{KCNH} 2$ loss-of-function mutations cause LQT2, whereas irregular rhythm and
EADs are precursors of ventricular arrhythmias in LQTS [34]. We detected differences in hERG-deficient lines at the multicellular level by high-throughput MEA analysis [35] (Fig. S1C). The results implied that hERG-deficient lines $(n=5 / 24)$ are more prone to irregular rhythm (Fig. 4b, e). Importantly, hERG-deficient lines displayed significant EADs (2/24) (Fig. 4d, f). EAD is a spontaneous membrane depolarisation, and when membrane potential depolarisation reaches a threshold, EAD may trigger action potentials prematurely and cause arrhythmia $[19,36]$. Conversely, control CMs $(n=24)$ exhibited no EADs or any other arrhythmogenic activities (Fig. 4a, c). To assess the sensitivity of the hERG-deficient lines to neurohormonal regulation [37], we administered 


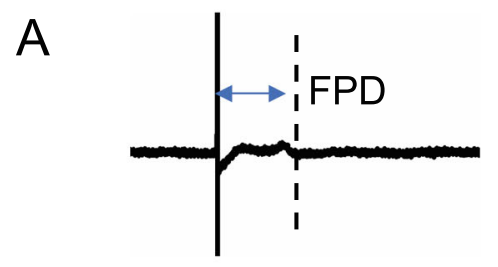

B

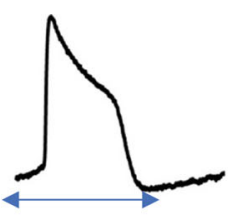

C WT

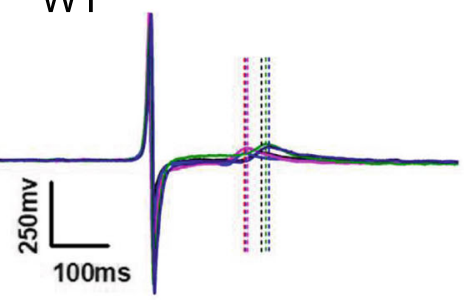

E

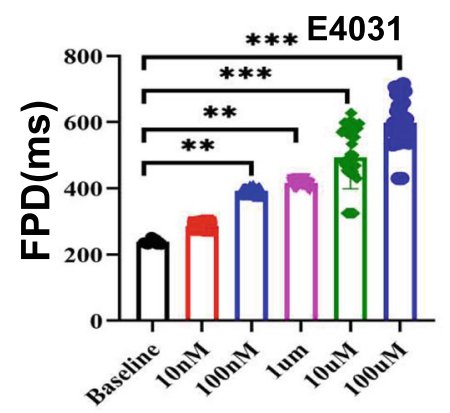

F

Action Potential Duration(APD)
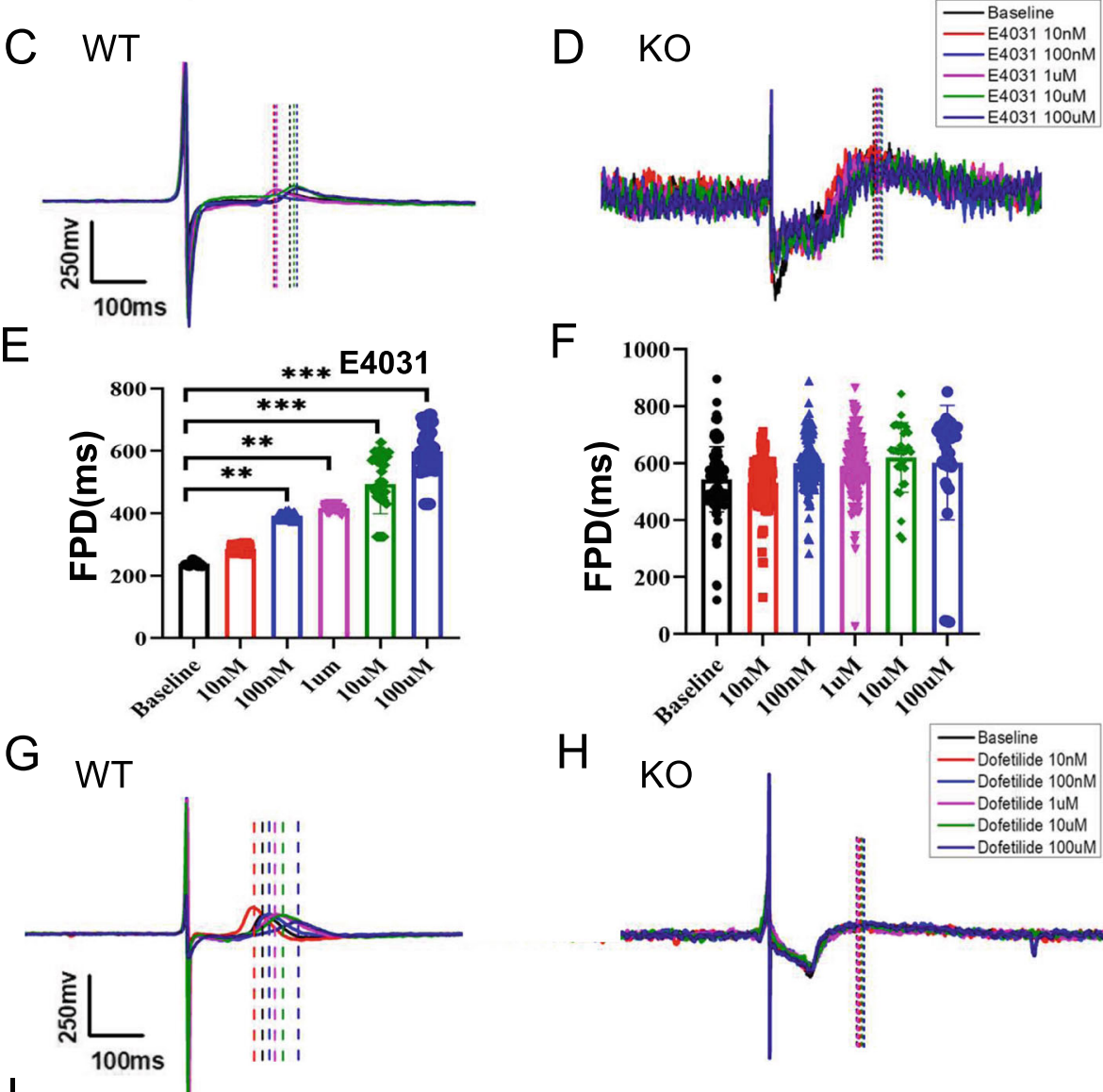

$\mathrm{H}$
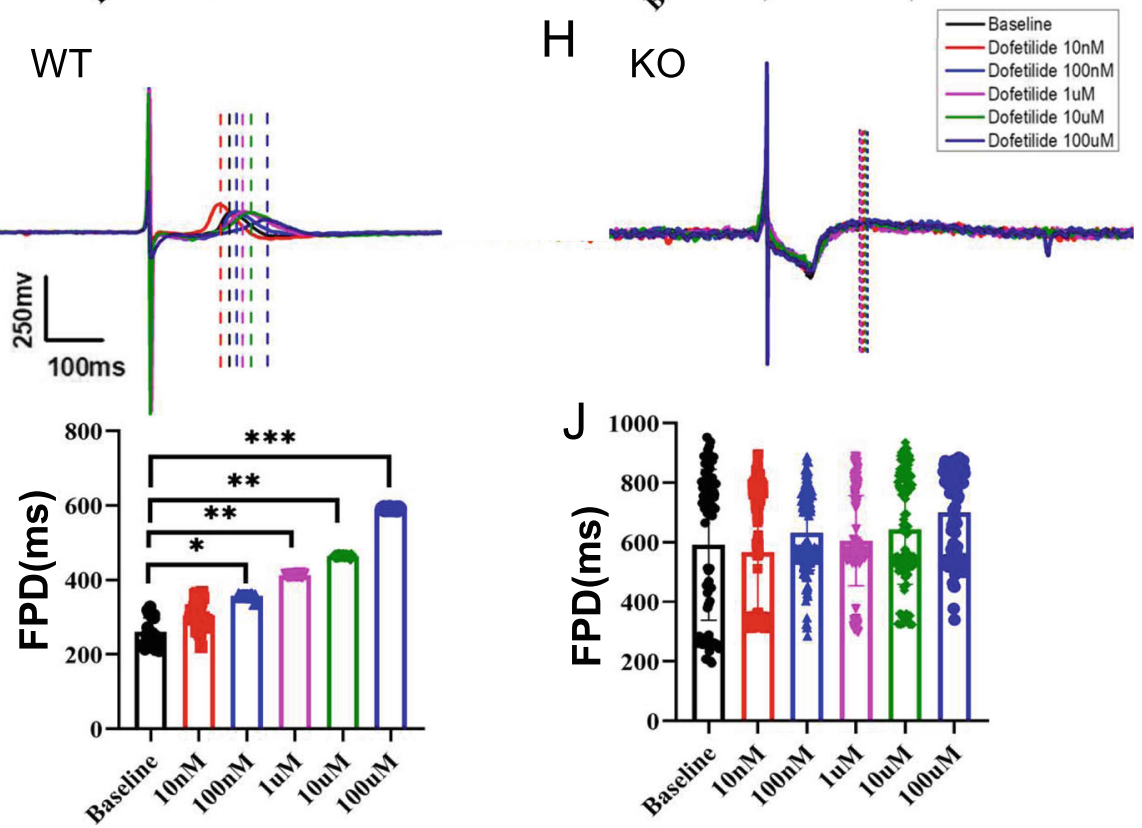

Fig. $\mathbf{3}$ KCNH2 deletion led to the loss of hERG function. $\mathbf{a}, \mathbf{b}$ Schematic diagrams of FPD and APD by MEA processing. $\mathbf{c}$, d The signals of FPD on different concentrations of E-4031 recorded in WT and KOs. e, $\mathbf{f}$ Quantification of FPD. $\mathbf{n}=3$ independent experiments, unpaired $t$ test. $\mathbf{g}$, $\mathbf{h}$ Signals of FPD on different concentrations of dofetilide recorded in WT and KOs. $\mathbf{i}, \mathbf{j}$ Quantification of FPD. $n=3$ independent experiments, unpaired $t$ test. $P<0.05$ was considered statistically significant $\left({ }^{*} P<0.05,{ }^{*} P<0.01,{ }^{* *} P<0.001,{ }^{* * *} P<0.0001\right)$

the adrenergic beta-agonist isoproterenol (ISO). The results revealed that ISO exhibited positive chronotropic action. We observed increased beating frequency (Fig. S2A, B), enhanced spike amplitude (Fig. S2D) and shortened FPD (Fig. S2C) with increasing drug concentrations. Overall, in vitro, the hERG-deficient model reproduced important electrophysiological changes that cause ventricular arrhythmia. 

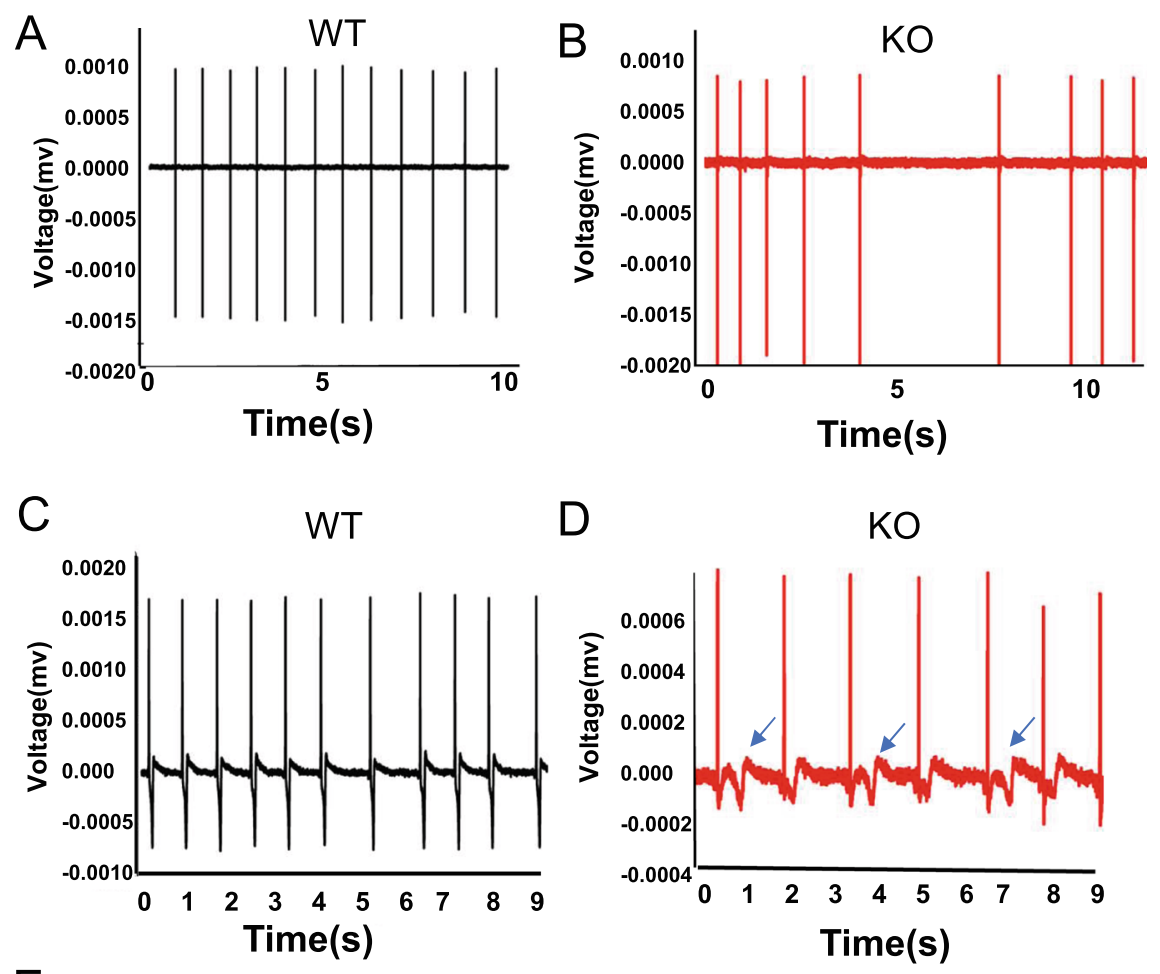

E

$\mathrm{F}$

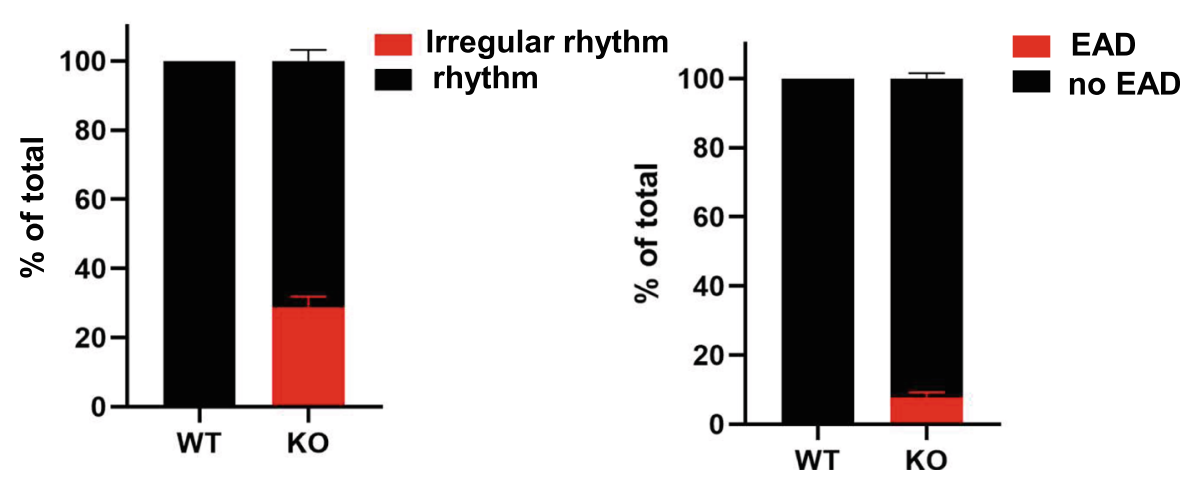

Fig. 4 hERG deficiency led to irregular rhythm and EAD. a, b Representative traces of irregular rhythm were recorded in hERG deficiency. $\mathbf{c}$, $\mathbf{d}$ Representative traces of EAD in FPD. The abnormal signals are labelled with blue arrows. $\mathbf{e}, \mathbf{f}$ Quantification of $\mathbf{b}$ and $\mathbf{d}$

\section{Baseline MEA electrophysiology}

To evaluate the baseline electrophysiological measurements of the hERG-deficient model, we selected preliminary mature CMs on day 30 and mature CMs on day 60 for separate testing [38]. Based on the recorded extracellular electrograms and FPD data analysis, we concluded that the FPD in hERG-deficient lines $(n=24)$ was longer than that in the control $(n=24)$ in hESCCMs (Fig. $5 \mathrm{a}-\mathrm{c}$ ). To identify the baseline value of the hERG-deficient lines more precisely, we used the cellbeating frequency to normalise the FPD to obtain the corrected FPD (FPDc), which was analogous to the corrective QT interval in the ECG (Fig. 5d). Likewise, the results showed marked APD prolongation in hERGdeficient hESC-CMs compared with controls (Fig. 5e-g). Moreover, the same hERG-deficient CMs derived from hPSC showed characteristically prolonged FPD and APD properties (data not shown). The above experimental results demonstrated that the hERG-deficient model exhibited obvious QT prolongation electrophysiological characteristics.

\section{Responses to other ion channel blockers}

To further characterise the pharmacology of the hERGdeficient model, we assessed cell sensitivity to other ion channel blockers. We first tested nifedipine, a potent 

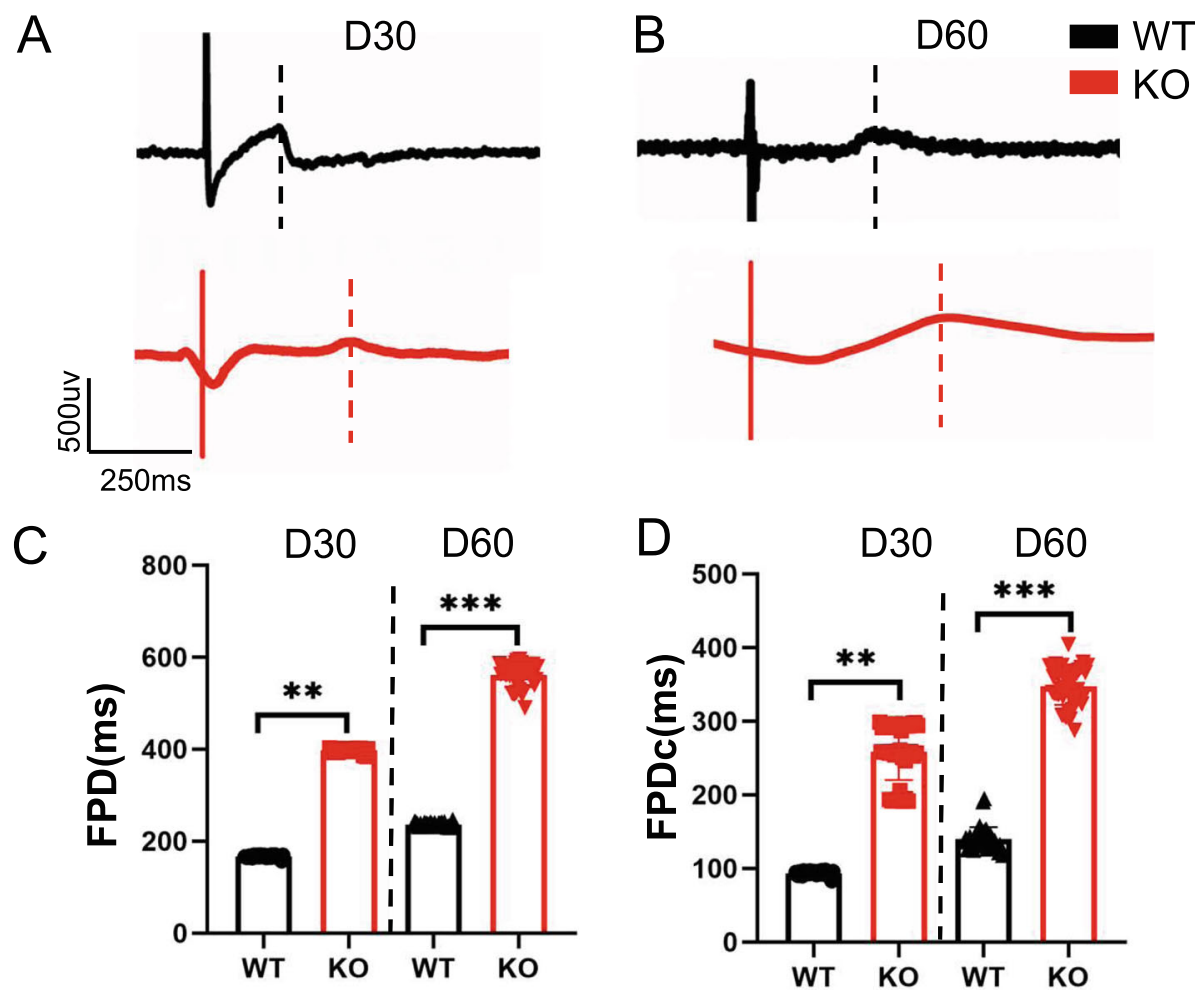

E

F

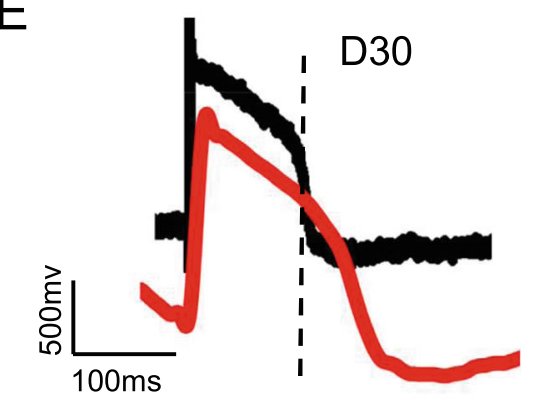

G
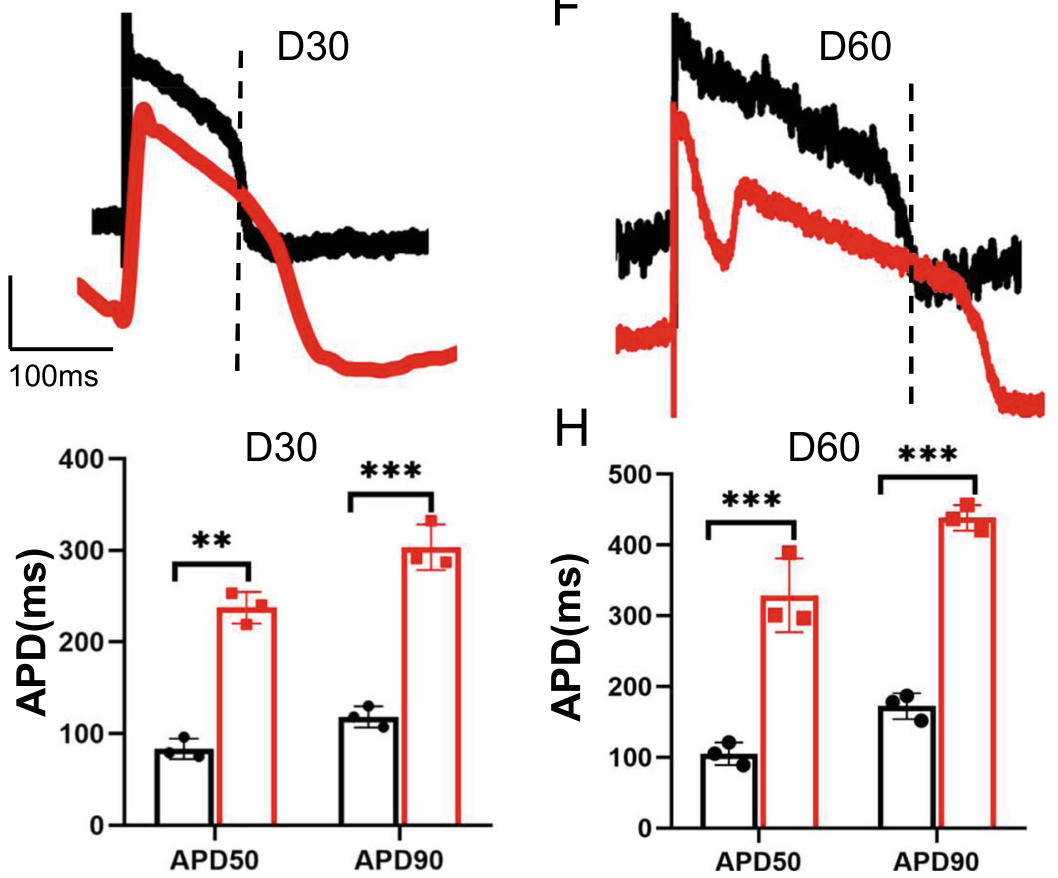

Fig. 5 FPD and APD prolongation in hERG-deficient lines. a, b Signals of FPD recorded on days 30 and 60 by MEA in WT and KOs. c, d Quantification of FPD and FPDC. $n=3$ independent experiments, unpaired $t$ test. e, f Recording trace of APD on days 30 and 60 in WT and KOs. g Quantification of AP at APD50, APD70 and APD90. $n=3$ independent experiments, unpaired $t$ test. $P<0.05$ was considered to be statistically significant $\left({ }^{*} P<0.05,{ }^{* *} P<0.01,{ }^{* *} P<0.001,{ }^{* * *} P<0.0001\right)$

dihydropyridine L-type calcium channel blocker [39]. Nifedipine resulted in a substantial reduction in FPD with $10 \mathrm{nM}$ or $100 \mathrm{nM}$ dosages (Fig. 6a). We then tested
$\mathrm{MgCl}_{2}$ for the clinical treatment of LQTS [40], and the results indicated that $\mathrm{MgCl}_{2}$ failed to shorten the QT interval but reduced the EAD development (Fig. 6b). 

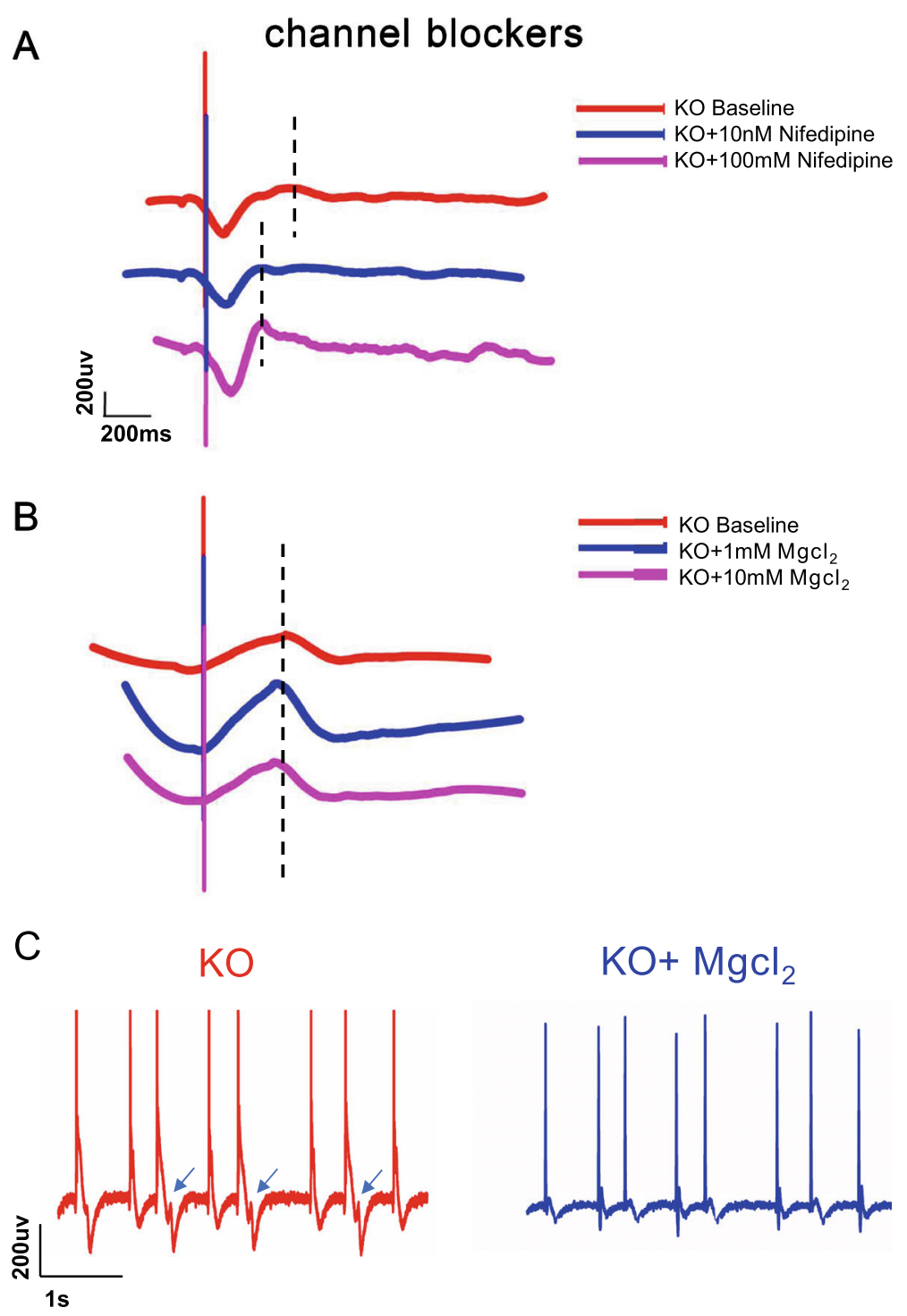

Fig. 6 hERG deficiency in response to other ion-channel blockers. a Representative FPD of KOs after treatment with nifedipine $(n=5)$. $\mathbf{b}$ Representative FPD of KOs after treatment with $\mathrm{MgCl}_{2}(n=5)$. $\mathbf{c}$, $\mathbf{d}$ Abrogation of EAD by $\mathrm{MgCl}_{2}$ intervention $(n=3)$

Overall, the hERG-deficient model can be used to screen other ion channel drugs to improve the abnormal phenotype.

\section{Discussion}

In this study, we generated a complete hERG -deficient model to characterise the pathogenesis of LQT2 and its important phenotypes in vitro. Crucially, the hERGdeficient model reproduced pronounced QT prolongation and rhythm disorders. Moreover, our results indicated that other ion channel blockers can partially correct abnormal phenotype. Our model provides an important platform for understanding the fundamental pathogenesis of hERG dysfunction, for defining genotype-phenotype correspondence and promoting drug development.
Three reports of human homozygous hERG mutations have been published, and all cases were related to severe LQTS and even embryonic lethality in infants [41-43]. Some homozygous carriers died in utero, while the ones that survived had severe cardiac electrophysiological disorders. This is of high interest because the same mutation led to different results. One possible hypothesis suggested by these cases is that in vivo even homozygous mutations with serious phenotypes are influenced by additional unknown factors. However, to date, the pathological mechanism of the complete deficiency of hERG is still unclear, and the appropriate methods or models for the study are unavailable. In cases of homozygous hERG mutations, the loss of functional $\mathrm{IKr}$ corresponds to 'human hERG knockout'. Thus, we established 
an in vitro hERG-hESC-derived CM model to explore the pathological mechanism of the hERG deficiency. One advantage of our model over others was that CMs derived from hESCs and hPSCs reproduced cardiac repolarisation that was strictly controlled by various internal and external ionic currents [44], whereas noncardiac cell models cannot fully simulate these subtle changes [45]. hESC and hPSC provide a valuable experimental platform for studying ion channel diseases [46]. Although hESC and hPSC are essentially different, such as they are derived from disparate sources, there is considerable consensus regarding the functional similarity of hESC and hPSC [47, 48]. Our data demonstrated that we were able to successfully establish an hERG-deficient hESC-derived CM model using CRISPR/Cas9. Further functional studies were also performed. E-4031 and Dofetilide are the most common selective $\mathrm{IKr}$ inhibitors [37]. Expectedly, cell lines with hERG deficiency were less sensitive to E-4031 than control cells. Dofetilide sensitivity was similar in the hERG-deficient model. The establishment of this hERG-deficient model was further supported by drug intervention. Importantly, this in vitro hERG-deficient model may facilitate the understanding of severe LQTS in foetuses.

$\mathrm{KCNH} 2$ is expressed abundantly in CMs where it participates in electrophysiological activities [2]; however, hERG is not believed to be involved in cardiac development [41]. In our study, the CM differentiation capacities of hERG-deficient lines were similar to those of the control. Additionally, no differences in myocardial subtype or myocardial structure were observed. These results agree with previous studies that reported that in humans with hERG homozygous mutations, the heart was structurally normal on echocardiography, with moderate ventricular function. Experiments of catecholamine-induced stress showed that an hERGdeficient cell line had a normal neurohormonal response. Most currents experience developmental maturation in cardiomyocytes. Generally, the QTc interval increases with age [49], and hESC-derived CMs mature over time during in vitro differentiation as they move towards an adult phenotype [50]. Consequently, our experiments included early mature (day 30 ) and late mature (day 60) CMs. As the CMs matured, the FPD, FPDc and APD on day 60 were longer than those on day 30 in both control and hERG-deficient cells.

KCNH2 mutations induce hERG dysfunction, which decreases the IKr current and delayed repolarisation. QT prolongation is one of the most important phenotypes. The Schwartz scoring system, which is used for clinical LQTS diagnosis, stipulates that a 460-470 ms QT interval represents medium risk, whereas $480 \mathrm{~ms}$ or more indicates a high risk [51]. Our results demonstrate that compared with the control, the FPD, FPDc and APD of the hERG-deficient model were significantly longer. However, these values in hERG-deficient cells were shorter than those reported in other LQT2 hPSC models and clinical values. One reason for this difference may be the inclusion of different cell lines. The cells were derived from different sources, and electrophysiological variability may have been increased by their distinct genetic backgrounds as well as the involvement of other genes in the regulation of electrophysiological activity [31]. Different studies in the past reported the same point mutation $\mathrm{A} 164 \mathrm{~V}$ in the pore region, and the difference between APD70 and APD90 of the A164V hPSC-CM from different patients was more than $200 \mathrm{~ms}$ $[19,20]$. These results also reflected that the functional changes in point mutations are unstable and difficult to standardise. Moreover, we used MEA analysis to detect electrophysiological activity at the multicellular level [26]. Compared with patch-clamp, the contact between cells in syncytium may result in other ion repolarisation compensation mechanisms to protect the abnormal milieu from serious deviation. Another important consideration is the beat times of $\mathrm{hESC}$-derived CMs, which generally range from 30 to 40 in vitro [19]. This is lower than the normal adult heart rate. Therefore, FPDc is much shorter than FPD.

Since our study compared different hERG statuses in the same system, an unambiguous genotype-phenotype relationship was ascertained. Many pathological mechanisms of heterozygous point mutations have been investigated [4], but the role of WT alleles in cases of heterozygous mutations is still unclear. Furthermore, their studies have not yet been stated clearly the mechanism of complete hERG deletion. hERG1b, a subunit that interacts with hERG (hERG1a), accounts for 19\% of the total hERG gene expression in the right atrium and $12 \%$ in the left ventricle. Due to the unique 'RXR' endoplasmic reticulum retention signal at the hERG1b Nterminus, it cannot be expressed on the membrane alone [52]. Using the masking effect of hERG1a, an hERG1a/ hERG1b composite channel is formed to complete the normal membrane deposition and effectively produce a stronger repolarisation current than the hERG1a complex alone. For this reason, the normal WT allele in cases with heterozygous mutations may also contribute to repolarisation. Thus, homozygous hERG deficiency is a more explicit and representative genotype-phenotype model for research. The overriding point in this aspect is that the hERG knockout model was easy to obtain and that the functional changes in hERG-deficient cell lines were more stable than that of point mutations. In addition, it also covered the functional changes in all mutations, which is a suitable model for studying QT prolongation and irregular rhythms. Furthermore, we captured irregular rhythms in this hERG-deficient 
model. Concomitantly, EAD also appeared. This is roughly analogous to the 2:1 atrioventricular block that occurs in homozygous hERG patients. Using the deficiency model, we also conducted pharmacological studies. We selected two drugs to treat homozygous hERG probands: Nifedipine and $\mathrm{MgCl}_{2}$. Our results showed that both 10-nM and 100-nM Nifedipine substantially shortened the QT interval. While $\mathrm{MgCl}_{2}$ failed to change the QT interval, it reduced the appearance of EADs. This is consistent with previous reports that stated that $\mathrm{MgCl}_{2}$ suppressed depolarisation-induced automaticity when APD was fixed [53].

\section{Conclusions}

In summary, we generated an hERG-deficient in vitro model using CRISPR/Cas9. The model exhibited marked QT prolongation, arrhythmia and sensitivity to other ion channel blockers and serves as an important tool to increase our understanding of the fundamental pathological mechanism of hERG dysfunction, define genotype-phenotype correspondence and facilitate drug development.

\section{Abbreviations}

LQT2: Long-QT syndrome type 2; hERG: Human ether-a-go-go-related gene; CM: Cardiomyocyte; hESC: Human embryonic stem cell; MEA: Microelectrode array; IKr: Delayed rectifier $K^{+}$channel; LQTS: Long-QT syndrome; APD: Action potential duration; hPSCs: Human pluripotent stem cells; WT: Wild-type; EAD: Early afterdepolarisation; $\mathrm{MgCl}_{2}$ : Magnesium chloride; sgRNA: Singlestranded guide RNA; PCR: Polymerase chain reaction; PFA: Paraformaldehyde; TNNT2: Troponin T; $\mathrm{KO}: \mathrm{KCNH}^{-1-} \mathrm{CMs}$; FPD: Field potential duration; ISO: Isoproterenol; FPDc: Corrected FPD

\section{Supplementary Information}

The online version contains supplementary material available at https://doi. org/10.1186/s13287-021-02346-1.

\section{Additional file 1: Figure S1. hERG deficiency did not affect} pluripotency of hESCs. a: Brightfield images showing the morphology of $\mathrm{WT}$ and $\mathrm{KCNH}^{-1-}$; b: In vitro differentiation of $\mathrm{KCNH}^{-1-}$ of ectoderm, endoderm, and mesoderm; $\mathbf{c}$ : Brightfield images showing CMs attachment to an electrode piece of MEA. Figure S2. Neurohormonal responses. a, b: After isoproterenol intervention, representative FPD recording in $\mathrm{KO}$; $\mathrm{C}$ : Signals of FPD on different concentrations of isoproterenol in KOs; d: Quantification of spike amplitude with different concentrations of isoproterenol. $\mathrm{n}=3$ independent experiments, $t$-test. $P$ $<0.05$ was considered to be statistically significant $\left({ }^{*} P<0.05\right.$, ${ }^{* *} P<0.01$, $\left.{ }^{* * *} P<0.001,{ }^{* * * *} P<0.0001\right)$.

\section{Acknowledgements}

The authors would like to thank Enago (www.enago.com) for providing English editing.

\section{Authors' contributions}

LF and LWJ conceived the idea and designed the experiments; CY and BR performed the cell experiments and data analysis. CY and Amina performed the manuscript preparation. WFJ and LYN are responsible for the cell culture experiments and the collection and assembly of data. ZSY, MSH and DT contributed to the molecular experiments. GTW and HCW contributed to the function analysis. JHF and JYX have been helping with revisions. All authors read and approved the final manuscript.

\section{Funding}

We gratefully acknowledge funding support from Beijing Natural Science Foundation No. Z190013, non-profit Central Research Institute Fund of Chinese Academy of Medical Sciences (2019PT320026) and National Natural Science Foundation of China Nos. 81970205.

\section{Availability of data and materials}

All data generated or analysed during this study are included in this published article.

\section{Declarations}

Ethics approval and consent to participate

Not applicable

\section{Consent for publication}

Not applicable

\section{Competing interests}

The authors declare that they have no competing interests.

\section{Author details}

${ }^{1}$ Beijing Laboratory for Cardiovascular Precision Medicine, The Key Laboratory of Biomedical Engineering for Cardiovascular Disease Research, The Key Laboratory of Remodeling-Related Cardiovascular Disease, Ministry of Education, Beijing Anzhen Hospital, Capital Medical University, Research Institute Building, Room 323, 2 Anzhen Road, Chaoyang District, Beijing 100029, China. ${ }^{2}$ Beijing Institute of Heart, Lung and Blood Vessel Diseases, Beijing 100029, China. ${ }^{3}$ Department of Cardiology, Peking University Third Hospital, Beijing 100191, China. ${ }^{4}$ State Key Laboratory of Cardiovascular Disease, National Center for Cardiovascular Diseases, Fuwai Hospital, Key Laboratory of Application of Pluripotent Stem Cells in Heart Regeneration, Chinese Academy of Medical Sciences and Peking Union Medical College, Beijing, China.

Received: 11 February 2021 Accepted: 19 April 2021

Published online: 07 May 2021

\section{References}

1. Warmke J, Ganetzky B. A family of potassium channel genes related to eag in Drosophila and mammals. Proc Natl Acad Sci U S A. 1994;91(8):3438-42. https://doi.org/10.1073/pnas.91.8.3438.

2. Sanguinetti M, Jiang C, Curran M, Keating M. A mechanistic link between an inherited and an acquired cardiac arrhythmia: HERG encodes the IKr potassium channel. Cell. 1995;81(2):299-307. https://doi.org/10.1016/00928674(95)90340-2.

3. Cheng J, Kodama I. Two components of delayed rectifier K+ current in heart: molecular basis, functional diversity, and contribution to repolarization. Acta Pharmacol Sin. 2004;25(2):137-45.

4. Anderson C, Kuzmicki C, Childs R, Hintz C, Delisle B, January C. Large-scale mutational analysis of Kv11.1 reveals molecular insights into type 2 long QT syndrome. Nature Commun. 2014;5:5535.

5. Adler A, Novelli V, Amin A, Abiusi E, Care M, Nannenberg E, et al. An International, Multicentered, Evidence-Based Reappraisal of Genes Reported to Cause Congenital Long QT Syndrome. Circulation. 2020;141(6):418-28. https://doi.org/10.1161/CIRCULATIONAHA.119.043132.

6. Priori S, Wilde A, Horie M, Cho Y, Behr E, Berul C, et al. Executive summary: HRS/EHRA/APHRS expert consensus statement on the diagnosis and management of patients with inherited primary arrhythmia syndromes. Europace. 2013;15(10):1389-406. https://doi.org/10.1093/europace/eut272.

7. Singh M, Morin D, Link M. Sudden cardiac death in Long QT syndrome (LQTS), Brugada syndrome, and catecholaminergic polymorphic ventricular tachycardia (CPVT). Prog Cardiovasc Dis. 2019;62(3):227-34. https://doi.org/1 0.1016/j.pcad.2019.05.006.

8. Stansfeld P, Sutcliffe M, Mitcheson J. Molecular mechanisms for drug interactions with hERG that cause long QT syndrome. Expert Opin Drug Metab Toxicol. 2006;2(1):81-94. https://doi.org/10.1517/17425255.2.1.81.

9. Babij P, Askew G, Nieuwenhuijsen B, Su C, Bridal T, Jow B, et al. Inhibition of cardiac delayed rectifier $\mathrm{K}+$ current by overexpression of the long-QT syndrome HERG G628S mutation in transgenic mice. Circ Res. 1998;83(6): 668-78. https://doi.org/10.1161/01.RES.83.6.668. 
10. Salama G, London B. Mouse models of long QT syndrome. J Physiol. 2007; 578(1):43-53. https://doi.org/10.1113/jphysiol.2006.118745.

11. Brunner M, Guo W, Mitchell G, Buckett P, Nerbonne J, Koren G. Characterization of mice with a combined suppression of I(to) and I(K,Slow). Am J Physiol Heart Circ Physiol. 2001;281(3):H1201-9. https://doi.org/10.11 52/ajpheart.2001.281.3.H1201.

12. $\mathrm{Xu} \mathrm{H}, \mathrm{Guo}$ W, Nerbonne J. Four kinetically distinct depolarization-activated K+ currents in adult mouse ventricular myocytes. J Gen Physiol. 1999;113(5): 661-78. https://doi.org/10.1085/jgp.113.5.661.

13. Liu G, Zhou J, Koren G. Single-channel properties of I K,slow1 and I K,slow2 in mouse ventricular myocytes. Pflugers Archiv Eur J Physiol. 2008;456(3): 541-7. https://doi.org/10.1007/s00424-007-0436-7.

14. Caputo L, Granados A, Lenzi J, Rosa A, Ait-Si-Ali S, Puri P, et al. Acute conversion of patient-derived Duchenne muscular dystrophy iPSC into myotubes reveals constitutive and inducible over-activation of TGF $\beta$ dependent pro-fibrotic signaling. Skeletal Muscle. 2020;10(1):13. https://doi. org/10.1186/s13395-020-00224-7.

15. Lan $F$, Lee A, Liang $P$, Sanchez-Freire V, Nguyen $P$, Wang L, et al. Abnormal calcium handling properties underlie familial hypertrophic cardiomyopathy pathology in patient-specific induced pluripotent stem cells. Cell Stem Cell. 2013;12(1):101-13. https://doi.org/10.1016/..stem.2012.10.010.

16. Ilic D, Ogilvie C. Concise review: human embryonic stem cells-what have we done? What are we doing? Where are we going? Stem cells (Dayton, Ohio). 2017;35:17-25.

17. Wang F, Kong J, Cui Y, Liu P, Wen J. Is Human-induced Pluripotent Stem Cell the Best Optimal? Chin Med J (Engl). 2018;131(7):852-6. https://doi. org/10.4103/0366-6999.228231

18. Ortmann D, Vallier L. Variability of human pluripotent stem cell lines. Curr Opin Genet Dev. 2017;46:179-85. https://doi.org/10.1016/.gde.2017.07.004.

19. Itzhaki I, Maizels L, Huber I, Zwi-Dantsis L, Caspi O, Winterstern A, et al. Modelling the long QT syndrome with induced pluripotent stem cells. Nature. 2011;471(7337):225-9. https://doi.org/10.1038/nature09747.

20. Wang Y, Liang P, Lan F, Wu H, Lisowski L, Gu M, et al. Genome editing of isogenic human induced pluripotent stem cells recapitulates long QT phenotype for drug testing. J Am Coll Cardiol. 2014;64(5):451-9. https://doi. org/10.1016/j.jacc.2014.04.057.

21. Garg P, Oikonomopoulos A, Chen H, Li Y, Lam C, Sallam K, et al. Genome Editing of Induced Pluripotent Stem Cells to Decipher Cardiac Channelopathy Variant. J Am Coll Cardiol. 2018;72(1):62-75. https://doi.org/1 0.1016/j.jacc.2018.04.041.

22. Brandão $K$, van den Brink L, Miller $D$, Grandela $C$, van Meer $B$, Mol M, et al. Isogenic sets of hiPSC-CMs harboring distinct KCNH2 mutations differ functionally and in susceptibility to drug-induced arrhythmias. Stem Cell Reports. 2020;15(5):1127-39. https://doi.org/10.1016/j.stemcr.2020.10.005.

23. Shah D, Prajapati C, Penttinen K, Cherian R, Koivumäki J, Alexanova A, Hyttinen J, Aalto-Setälä K. hiPSC-derived cardiomyocyte model of LQT2 syndrome derived from asymptomatic and symptomatic mutation carriers reproduces clinical differences in aggregates but not in single cells. Cells. 2020;9(5):1153. https://doi.org/10.3390/cells9051153.

24. Qi T, Wu F, Xie Y, Gao S, Li M, Pu J, et al. Base editing mediated generation of point mutations into human pluripotent stem cells for modeling disease. Front Cell Dev Biol. 2020;8:590581. https://doi.org/10.3389/fcell.2020.590581.

25. Yoshinaga D, Baba S, Makiyama T, Shibata H, Hirata T, Akagi K, et al. Phenotype-based high-throughput classification of long QT syndrome subtypes using human induced pluripotent stem cells. Stem Cell Reports. 2019;13(2):394-404. https://doi.org/10.1016/j.stemcr.2019.06.007.

26. Fodstad H, Bendahhou S, Rougier J, Laitinen-Forsblom P, Barhanin J, Abriel $\mathrm{H}$, et al. Molecular characterization of two founder mutations causing long QT syndrome and identification of compound heterozygous patients. Ann Med. 2006;38(4):294-304. https://doi.org/10.1080/07853890600756065.

27. Lahti A, Kujala V, Chapman H, Koivisto A, Pekkanen-Mattila M, Kerkelä E, et al. Model for long QT syndrome type 2 using human iPS cells demonstrates arrhythmogenic characteristics in cell culture. Dis Model Mech. 2012:5(2):220-30. https://doi.org/10.1242/dmm.008409.

28. Burridge P, Matsa E, Shukla P, Lin Z, Churko J, Ebert A, et al. Chemically defined generation of human cardiomyocytes. Nat Methods. 2014;11(8): 855-60. https://doi.org/10.1038/nmeth.2999.

29. Tohyama S, Hattori F, Sano M, Hishiki T, Nagahata Y, Matsuura T, et al. Distinct metabolic flow enables large-scale purification of mouse and human pluripotent stem cell-derived cardiomyocytes. Cell Stem Cell. 2013; 12(1):127-37. https://doi.org/10.1016/j.stem.2012.09.013.
30. Xie Y, Wang D, Lan F, Wei G, Ni T, Chai R, et al. An episomal vector-based CRIS PR/Cas9 system for highly efficient gene knockout in human pluripotent stem cells. Sci Rep. 2017;7(1):2320. https://doi.org/10.1038/s41598-017-02456-y.

31. Bellin M, Casini S, Davis R, D'Aniello C, Haas J, Ward-van Oostwaard D, et al. Isogenic human pluripotent stem cell pairs reveal the role of a $\mathrm{KCNH} 2$ mutation in long-QT syndrome. EMBO J. 2013;32(24):3161-75. https://doi. org/10.1038/emboj.2013.240.

32. Jouni M, Si-Tayeb K, Es-Salah-Lamoureux Z, Latypova X, Champon B, Caillaud A, et al. Toward personalized medicine: using cardiomyocytes differentiated from urine-derived pluripotent stem cells to recapitulate electrophysiological characteristics of type 2 long QT syndrome. J Am Heart Assoc. 2015;4:e002159.

33. Cheng G, Wu J, Han W, Sun C. F463L increases the potential of dofetilide on human ether-a-go-go-related gene (hERG) channels. Microsc Res Tech. 2018;81 (6):663-8. https://doi.org/10.1002/jemt.23021.

34. Belardinelli L, Antzelevitch C, Vos M. Assessing predictors of drug-induced torsade de pointes. Trends Pharmacol Sci. 2003;24(12):619-25. https://doi. org/10.1016/j.tips.2003.10.002.

35. Hayes H, Nicolini A, Arrowood C, Chvatal S, Wolfson D, Cho H, et al. Novel method for action potential measurements from intact cardiac monolayers with multiwell microelectrode array technology. Sci Rep. 2019;9(1):11893. https://doi.org/10.1038/s41598-019-48174-5.

36. Marbán E. Cardiac channelopathies. Nature. 2002;415(6868):213-8. https:// doi.org/10.1038/415213a

37. Navarrete E, Liang P, Lan F, Sanchez-Freire V, Simmons C, Gong T, et al. Screening drug-induced arrhythmia [corrected] using human induced pluripotent stem cell-derived cardiomyocytes and low-impedance microelectrode arrays. Circulation. 2013;128(11_suppl_1):S3-13. https://doi. org/10.1161/CIRCULATIONAHA.112.000570.

38. Ono M, Burgess D, Schroder E, Elayi C, Anderson C, January C, et al. Long QT Syndrome type 2: emerging strategies for correcting class $2 \mathrm{KCNH} 2$ (hERG) mutations and identifying new patients. Biomolecules. 2020;10(8). https://doi.org/10.3390/biom10081144.

39. Peng S, Lacerda A, Kirsch G, Brown A, Bruening-Wright A. The action potential and comparative pharmacology of stem cell-derived human cardiomyocytes. J Pharmacol Toxicol Methods. 2010;61(3):277-86. https:// doi.org/10.1016/j.vascn.2010.01.014.

40. Hoshino K, Ogawa K, Hishitani T, Isobe T, Eto Y. Optimal administration dosage of magnesium sulfate for torsades de pointes in children with long QT syndrome. J Am Coll Nutr. 2004;23(5):497S-500S. https://doi.org/10.1080/ 07315724.2004.10719388.

41. Hoorntje T, Alders M, van Tintelen P, van der Lip K, Sreeram N, van der Wal A, et al. Homozygous premature truncation of the HERG protein : the human HERG knockout. Circulation. 1999;100(12):1264-7. https://doi.org/1 0.1161/01.CIR.100.12.1264.

42. Johnson W, Yang P, Yang T, Lau Y, Mostella B, Wolff D, et al. Clinical, genetic, and biophysical characterization of a homozygous HERG mutation causing severe neonatal long QT syndrome. Pediatr Res. 2003;53(5):744-8. https://doi.org/10.1203/01.PDR.0000059750.17002.B6.

43. Piippo K, Laitinen P, Swan H, Toivonen L, Viitasalo M, Pasternack M, et al. Homozygosity for a HERG potassium channel mutation causes a severe form of long QT syndrome: identification of an apparent founder mutation in the Finns. J Am Coll Cardiol. 2000;35(7):1919-25. https://doi.org/10.1016/ S0735-1097(00)00636-7.

44. Bohnen M, Peng G, Robey S, Terrenoire C, lyer V, Sampson K, et al. Molecular pathophysiology of congenital long QT syndrome. Physiol Rev. 2017;97(1):89-134. https://doi.org/10.1152/physrev.00008.2016.

45. Nalos L, Varkevisser R, Jonsson M, Houtman M, Beekman J, van der Nagel R, et al. Comparison of the IKr blockers moxifloxacin, dofetilide and E-4031 in five screening models of pro-arrhythmia reveals lack of specificity of isolated cardiomyocytes. Br J Pharmacol. 2012;165(2):467-78. https://doi. org/10.1111/j.1476-5381.2011.01558.x.

46. Chiamvimonvat N, Chen-Izu Y, Clancy C, Deschenes I, Dobrev D, Heijman J, et al. Potassium currents in the heart: functional roles in repolarization, arrhythmia and therapeutics. J Physiol. 2017;595(7):2229-52. https://doi.org/10.1113/JP272883.

47. Damdimopoulou P, Rodin S, Stenfelt S, Antonsson L, Tryggvason K, Hovatta O. Human embryonic stem cells. Best practice \& research. Clin Obstet Gynaecol. 2016;31:2-12. https://doi.org/10.1016/j.bpobgyn.2015.08.010.

48. Ohnuki M, Takahashi K. Present and future challenges of induced pluripotent stem cells. Philosophical transactions of the Royal Society of London. Series B, Biol Sci. 2015;370:20140367. 
49. Rabkin S. Impact of Age and Sex on QT Prolongation in patients receiving psychotropics. Canadian journal of psychiatry. Revue Canadienne de Psychiatrie. 2015;60(5):206-14. https://doi.org/10.1177/070674371506000502.

50. Sartiani L, Bettiol E, Stillitano F, Mugelli A, Cerbai E, Jaconi M. Developmental changes in cardiomyocytes differentiated from human embryonic stem cells: a molecular and electrophysiological approach. Stem Cells (Dayton, Ohio). 2007;25:1136-44.

51. Dagradi F, Spazzolini C, Castelletti S, Pedrazzini M, Kotta M, Crotti L, et al. Exercise training-induced repolarization abnormalities masquerading as congenital long QT syndrome. Circulation. 2020;142(25):2405-15. https://doi. org/10.1161/CIRCULATIONAHA.120.048916.

52. Phartiyal $P$, Jones $E$, Robertson $G$. Heteromeric assembly of human ether-àgo-go-related gene (hERG) 1a/1b channels occurs cotranslationally via Nterminal interactions. J Biol Chem. 2007;282(13):9874-82. https://doi.org/10.1 074/jbc.M610875200.

53. Kaseda S, Gilmour R, Zipes D. Depressant effect of magnesium on early afterdepolarizations and triggered activity induced by cesium, quinidine, and 4-aminopyridine in canine cardiac Purkinje fibers. Am Heart J. 1989; 118(3):458-66. https://doi.org/10.1016/0002-8703(89)90258-5.

\section{Publisher's Note}

Springer Nature remains neutral with regard to jurisdictional claims in published maps and institutional affiliations.

Ready to submit your research? Choose BMC and benefit from:

- fast, convenient online submission

- thorough peer review by experienced researchers in your field

- rapid publication on acceptance

- support for research data, including large and complex data types

- gold Open Access which fosters wider collaboration and increased citations

- maximum visibility for your research: over $100 \mathrm{M}$ website views per year

At $\mathrm{BMC}$, research is always in progress.

Learn more biomedcentral.com/submissions 